\title{
"CREATIVIDAD: NACE O SE ADQUIERE?' (Una aproximación al más grande enigma de la Cultura Contemporánea)
}

\author{
"CREATIVITY: BORN OR MADE?" \\ (An approach to the biggest enigma of contemporary culture)
}

FECHA DE RECIBO: OCTUBRE 31, 2012

FECHA DE ACEPTACIÓN: DICIEMBRE 20, 2012

\section{ODÍN ARREGOCÉS SERRANO}

\author{
Profesor de la Facultad de Arquitectura, Arte y Diseño de la Universidad Autónoma del Caribe
} arregodin@yahoo.es

\begin{abstract}
RESUMEN:
El presente artículo se enfoca a la reflexión sobre la mayor vanguardia creativa que hoy existe: la creatividad misma. Es el producto de una serie de entrevistas con personas con prestigio de ser creativas y del análisis del pensamiento de autores que han enfocado el problema desde ángulos disímiles. Los expertos siempre abordan el problema diciendo que "es un concepto confuso y por lo tanto desvalorizado". El artículo concluye con una pregunta. ¿Nace o se adquiere? La mayoría concuerda en afirmar que puede aprenderse. Creatividad significa dos cosas: novedad y trascendencia. Pero no todo lo nuevo es creativo. Nada en la vida está terminado. La vida misma es un proceso de permanente metamorfosis. No existe forma humana posible de impedir el ejercicio de la imaginación. Se trata de un nivel de conciencia perceptiva superior del alma y del conocimiento.
\end{abstract}

\section{PALABRAS CLAVE:}

Vanguardia, Creatividad, Cambio, Don, Proceso, Misterio, Novedad, Transcendencia, Gestar, Visión, Vanguardia

\section{ABSTRACT:}

This paper aims to reflect on the most creative art that exists today: creativity itself. It is the product of a series of interviews with people with prestige of being creative and thinking analysis of authors who have approached the problem from dissimilar angles. Experts always addressed the problem by saying that "it is a confusing and devalued concept". The article concludes with two questions. Are they born or acquired? Most agree state that can be learned. Creativity means two things: novelty and significance. But not everything new is creative. Nothing in life is finished. Life itself is a process of constant metamorphosis. There is no way humanly possible to prevent the exercise of the imagination. This is a higher level of perceptual awareness and knowledge of the soul.

\section{KEYWORDS:}

Creativity, Change, Gift, Process, Mystery, Novelty, Trascendence, Gestate, Vision 


\section{INTRODUCCIÓN}

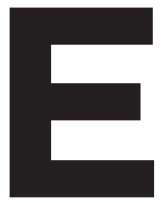

I término "vanguardia creativa", tiene como significado la creatividad misma. Dicho en otras palabras, la mayor "vanguardia creativa", que hoy existe, es la creatividad misma.

“Heráclito escribió 500 años antes de Cristo una inquietante sentencia en torno a la permanencia del cambio!. «En la vida todo se acaba, lo único permanente es el cambio»¿Pero de qué clase de cambio hablaba Heráclito?. (Citado por Jean Paul Sartre - 1945)

¿Qué significa el término CREATIVIDAD? No existe casi ningún análisis escrito sobre este fenómeno exclusivo de la vida "inteligente". No hay casi nada ni en archivos, ni en informes, ni en ningún tipo de literatura sobre este inquietante asunto, hoy por hoy en todo el planeta y los anales de su cultura contemporánea.

Es inaplazable incursionar en la búsqueda de la creatividad. ¿Qué es la creatividad? ¿Es un "don exclusivo de los genios", o puede gestarse? Las respuestas a esta pregunta son el resultado de entrevistas a personas con prestigio de ser creativas en las artes, la ciencia y los negocios y de analizar cómo "saltaban de lo inesperado a lo inspirado" en sus respectivos campos; al igual que a una gran diversidad de personas consideradas comúnmente "creativas".

\section{"La palabra creatividad es uno de los términos menos investigado y más polémico producto de la mente abstracta del hombre."}

\section{LA CREATIVIDAD: ARGUMENTO COMPLEJO}

Los expertos siempre han abordado el problema diciendo que "la creatividad es un concepto confuso, y por lo tanto, desvalorizado"(R. Cuero, 2012). Fue necesario, a partir de ahí, emprender la tarea de averiguar cuanto fuera posible sobre la creatividad. Explorar el verdadero significado del término. Lo que han opinado científicos, eruditos, siquiatras, sicólogos, historiadores, educadores, sociólogos y filósofos, cuya carrera había estado dedicada a explorar "la creatividad".

El novelista norteamericano Bernard Malamud (1961) declaraba: "La creatividad como argumento, es una cuestión compleja. Quizá alguna vez en el futuro se encontrará efectivamente el tejido genético que le da sustento. No quiero estar allí cuando eso suceda. Deseo que la creatividad artística siga siendo siempre un misterio".

Geoge Prince (1970), filósofo norteamericano contemporáneo, autor de "The practice of Creativity" reconoce que "alguna vez consideró la creatividad como un acto extraordinario, que daba origen a algo nuevo y útil para la humanidad", pero que ahora la ve "como algo menos cósmico y más común, un asunto cotidiano, una forma de pensar y actuar que se relaciona, en última instancia, con el aprendizaje y la capacidad de modificar, no sólo el propio ser, sino la situación personal, las circunstancias vitales de su entorno".

Es esta la tensión básica entre quienes consideran que "la creatividad es un misterio", posiblemente un don exclusivo del genio, (los "utopistas" - finales del siglo XIX), y quienes creen que "debe desmitificarse, fomentarse e incluso democratizarse" (los "racionalistas"- comienzos del siglo XX).

Una escuela, por un lado, no quiere que se intente dividir la creatividad en variables científicamente definidas. La escuela que así se enfoca es la escuela utopista, que se caracteriza por concebir la creatividad como un hecho indescifrable y enigmático de la mente abstracta del hombre.

Otra considera que "la creatividad pertenece a todos, que es tan inseparable de la condición humana, como la palabra". Con esta óptica, la escuela racionalista describe la creatividad enmarcándola en un plano definitorio de la misma condición humana, donde el más obvio instrumento para la supervivencia y mejoramiento de la especie.

Esta última escuela sostiene - tal como lo expresó el finado siquiatra británico Lawrence Kubie (1964)“que si la mayoría de nosotros viene siguiendo las mismas ideas conocidas, esto no se debe a que carezcamos de creatividad, sino a que la sofocamos". Si el impedimento es descubierto, identificado y exorcizado, la creatividad florecerá.

En realidad, el debate representa no solo opiniones contrarias sobre la creatividad, sino también ideas divergentes sobre la naturaleza humana.

La palabra creatividad es uno de los términos menos investigado y más polémico producto de la mente abstracta del hombre.

La primera gran conclusión conduce a pensar que la palabra "creatividad" significa dos cosas: novedad y trascendencia. Lo que se crea es nuevo, y lo nuevo abre caminos para expandir las posibilidades humanas.

\section{"El fiel de la balanza del esquema innovador humano es el conservacionismo, el punto intermedio entre destrucción y creación. Toda actividad creadora rompe con el pasado, pero permanece en deuda con el mismo."}

Durante mucho tiempo, las religiones y las filosofías humanas pensaron que Dios había creado todo lo que había de crearse. Los mortales sólo tenían que descubrir lo que ya estaba impreso en el universo. No es cosa humana el crear sino el ordenar. El ser humano no es agente de cambio sino simple cómplice. Federico Nietzche,(2011) el filósofo alemán escribió sobre el 
arte de crear: "La verdad se vive, no se enseña". El cambio de los valores, es el cambio del que crea siempre. El que ha de crear, destruye. Aquel que quiere ser creador habrá primeramente que ser destructor y hacer pedazos los antiguos valores. Así el supremo mal, hará parte del supremo bien, pero el supremo bien es creador. Recrea, lo que destruye...".

"Ninguna persona puede ver y comprender en otros, lo que ella misma no ha vivido". (Federico Nietzche, 2011).

“Dios creó un rompecabezas cósmico y nuestra tarea es armarlo como era su intención. Nada más"(Theilhard de Chardin, 2011)

Ante tales hipótesis, no es sorprendente que la idea de analizar la creatividad humana no figurara en el quehacer principal de la conciencia colectiva, antes del siglo XVIII, o que el término creatividad, no fuera incluído en el Oxford English Dictionary sino hasta 1933. La primera vez que se mencionó el término "creatividad" en una reunión de arquitectos, fue en el (CIAM)- Primer Congreso Internacional de Arquitectura Moderna en La Sarraz, Francia, en 1928. Nunca antes se había puesto tal término en los labios de un profesional de la Arquitectura o el Diseño.

\section{" Casi lo único en que concuerdan los expertos es en que la creatividad ocurre cuando dos ideas aparentemente inconexas se unen de tal manera que producen algo nuevo, un nuevo orden de cosas."}

Sin duda, algo había ocurrido en la cultura universal que habría de cambiar esa visión de un mundo predeterminado. Jacob Burckhardt (1959), historiador del arte del siglo XIX, rastrea el origen de ese "algo" en la Italia del Renacimiento, cuando el hombre empezó a deleitarse en la creación de su propio mundo, en lugar de aceptar pasivamente lo que Dios había creado para él.

Albert Rabil Jr. (hijo), (1988) profesor emérito de la Universidad del Estado de Nueva York, considera que "la Revolución Francesa es una escisión importante". Toda una nación - escribe - incluida su cultura, su idiosincrasia y sus raíces míticas, fue completamente transformada por la acción humana".

La antes dominante aristocracia, ahora decadente y agotada desde el punto de vista de la imaginación, cedió el lugar a los burgueses de clase media e industrializada, quienes eran ya los precursores de una nueva sociedad de masas. Una nueva fuerza social capaz de comprender que para sobrevivir no hace falta la imaginación. Para vivir plenamente, se necesita ser creativo, como condición sine qua non. Como secuela de la revolución entre los poetas y filósofos románticos, elevados a conductores sociales por una revolución cultural como la Francesa, floreció una "nueva visión" de los seres humanos como autores y no puramente actores del drama del cambio. La revolución francesa puede hoy ser llamada "la primera piedra de la modernidad humana"(Rabil y D`amico, 1988), la que demostró que "las utopías son el prerrequisito hacía la nueva realidad" (Rabil, 1988).

Gracias a la imaginación, decían, la mente humana puede crear cualitativamente nuevas ideas y realidades. "La imaginación ha llegado al poder", escribió Marat (1794). Aunque los románticos reconocían que muchos antecesores suyos habían empleado la imaginación, fueron los primeros en reconocerla como fuerza creadora, subraya Rabil (1988), en tal forma que de sus reflexiones surgió una nueva comprensión de la cultura.

Ciertamente, lo nuevo tiene muy pocos amigos. Sobre todo al comienzo. Todo el mundo teme a lo que no conoce. $Y$ es mejor malo conocido que bueno por conocer. Aparte de que lo viejo recuerda permanentemente la estabilidad que ofrece permanecer leal a acciones y mecanismos que operan dentro de un statu quo seguro y libre de sobresaltos inesperados.

Es más fácil adherir a lo conocido. $Y$ hasta rentable. Ciertamente, esa visión distinta de las cosas provocaba estremecimientos profundos a los teólogos de todo el mundo. Se venía abajo la idea de un orden de cosas fijo, aunque oculto, que esperaba ser descubierto por el hombre, pero se oponía a sus intenciones. Sin duda, el proceso fue lento, pero seguro. Incluso los filósofos - Hegel primero, más tarde Marx - trataron de guardar las apariencias y ubicar este nuevo punto de partida dentro de un proceso histórico determinado desde el interior. Fue necesario que la voz solitaria pero enérgica de Sören Kierkegaard (1971), proclamará la "muerte del determinismo", y afirmará de manera casi solemne, que "el ser humano no tiene una esencia predeterminada, sino que se define por la libertad y la capacidad de crear, y que el carácter proviene de la creación"

Las leyes de la entropía seguían siendo tabú. Los teólogos se negaba aún a reconocer que el acto creativo humano era el único verdadero antídoto efectivo contra ese "extraño e irrefrenable deseo de la materia de retornar al caos primigenio del que proviene" (Albert Einstein, 1879 - 1902).

Decir que los seres humanos tienen capacidad creativa no es negar la función ordenadora de la mente humana, ni la naturaleza de su pensamiento. Durante los años 50`s y 60`s, el educador canadiense James Guilford (1963) y sus colegas descubrieron que ambos tipos de pensamiento eran característicos del ser humano: el pensamiento convergente, que precisa y, por decirlo así, tiende sistemáticamente hacia una respuesta, y el pensamiento divergente, que se aleja de un centro, quizás en varias direcciones a la vez, buscando caminos, vías nuevas de investigación y no un destino en particular y mucho menos predeterminado.

Los científicos, por lo general, se valen del pensamiento convergente. Intentan resolver problemas, empleando un paradigma aceptado que les indica las leyes y reglas de juego de su disciplina. Algunas veces, no obstante, el pensamiento convergente falla: el paradigma no logra abarcar el problema 
que debe resolverse. La creación de un nuevo paradigma requiere del pensamiento divergente. Sin embargo, el científico había utilizado el pensamiento convergente antes de buscar un nuevo paradigma (debe conocerse a fondo la ciencia que se pretende reformar) y debe hacerlo nuevamente, después de crear el nuevo paradigma, para verificarlo y poner a prueba la serie de problemas que es capaz de desentrañar. En resumen, el pensamiento convergente fluye ininterrumpidamente desde el pasado y conduce a conclusiones predecibles sobre la base de lo anterior, de lo conocido y probado como éxito.

El pensamiento divergente, rompe en muchos aspectos con el pasado y conduce a conclusiones impredecibles sobre la base de lo precedente. Ambos son fundamentalmente diferentes, pero son como el bien y el mal, que están irremediablemente relacionados y no podría existir el uno sin el otro.

\section{" Algunos científicos concuerdan en que, la capacidad creativa -en cualquier forma que se la conciba, puede aprenderse."}

La siguiente anécdota ilustra claramente esa interrelación entre las dos corrientes del pensamiento creativo humano: Sir Isaac Newton, quien en un año creó el cálculo, la primera teoría matemática de la naturaleza de la luz y la física moderna, está considerando apropiadamente como uno de los más grandes genios científicos de toda la historia human, pasó la mayor parte de su vida, tras de elaborar su "nueva física", tratando de crear un paradigma exhaustivo similar para una "nueva química moderna", pero fracasó. Nunca lo logró. ¿Por qué? Porque la ciencia misma no se había desarrollado aun lo bastante para que, incluso un Newton pudiera "ver" el nuevo orden que buscaba y que hoy se llama "química moderna". Eso vino más de 100 años después de la muerte de Newton.

El adelanto de Newton en la física fue nuevo y no se podía haber previsto en función de lo que se había hecho antes. Y, sin embargo, lo antes logrado en el desarrollo de las matemáticas, la astronomía y la mecánica, era suficientemente poderoso para hacer posible un paradigma nuevo y exhaustivo. Newton mismo reconoció todo esto como cierto cuando dijo que estaba "parado sobre los hombros de gigantes". Pero, los "hombros de los gigantes" no eran todavía tan altos en la química de su tiempo, y por eso ni siquiera su genio pudo abrirse camino.

La anterior puede considerarse como prueba fehaciente de que cualquier proyecto humano coherente es el resultado de un proceso en el tiempo, a donde los espacios van cambiando de contextura, forma y tamaño hasta que logran cambiar hasta el proceso mismo, convirtiéndolo en uno "nuevo". La variable tiempo es la única capaz de revaluar el proceso total.

El célebre científico atómico Robert Oppenheimer (1955) es- cribía en 1940: “la incapacidad de captar la relación entre la creatividad y la tradición se debe con frecuencia a la ignorancia respecto a los recursos que ha utilizado el innovador para plantear sus nuevas tesis radicales". El fiel de la balanza del esquema innovador humano es el conservacionismo, el punto intermedio entre destrucción y creación. Toda actividad creadora rompe con el pasado, pero permanece en deuda con el mismo.

"Nunca podemos juzgar la creatividad solo en función de los procesos internos de una persona" (Samson Raphaelson, 1966). Lo que sucede es siempre un proceso que vincula a una persona con el mundo, incluso con el pasado. Es siempre algo integral, que principia en la infancia, aún antes.

La actividad creadora brota de raíces profundas que nunca se cortan del todo y que nunca se detienen, aunque sean trascendidas por aquella, "la capacidad creativa del ser humano, siempre está por encima de su propia naturaleza y trasciende sus limitaciones. Es un algo mágico que "se tiene o no se tiene". (Lubitsch, 1966).

Samson Raphaelson (1966), el autor teatral norteamericano, afirma que "el impulso de ser creativo tiene sus raíces en un pasado remoto que ya no actúa conscientemente pero subsiste". "Todos los inventos son ejemplos de desviaciones de la tradición, pero ninguno pudo haberse realizado sin ésta", escribió Thomas Alva Edison, el científico norteamericano creador, entre otros muchos inventos, de la bombilla de luz incandescente y considerado uno de los mayores genios creadores de la modernidad humana.

Es así como la gente creativa contempla con frecuencia algo del pasado, que es el resultado del pensamiento convergente, y al pensar en ello divergentemente, descubre una nueva forma de usar un objeto conocido. Se busca en lo fácil, encontrar lo inusitado. En lugar de dirigir su pensamiento hacía soluciones viejas, lo encausan en otra dirección, con lo que dan el salto de lo inesperado a lo inspirado. Los poetas lo logran con metáforas y símiles: "ella era un espectro de delicia, cuando refulgió por primera vez ante mi vista". "Si no vas a venir, por favor no vengas, pero rápido".(Volpe, 1999).

Se puede pensar creativamente sobre casi cualquier cosa, si se aprende a relacionar y unir lo que a primera vista parece difícil de acoplar. Es lo que hace posible que un profesor ambientalista de la Universidad de Phoenix, Arizona, especialista en basura, pueda enseñar lo que es la civilización contemporánea, por medio de la descripción de lo que la gente desecha. Así mismo, el artista minimalista de Nueva York, Kurt Grading (1981), crea de objetos callejeros ordinarios obras de arte. $Y$ en una planta de aguas negras, al oeste de Milán, Italia, se utilizan lombrices de tierra para convertir el cieno de alcantarilla en humus agrícola.

¿Por qué no basta el pensamiento convergente? ¿Por qué se debe pensar y actuar creativamente? ¿Por qué hay demasiadas anomalías, demasiados acertijos sin explicación e inexplicables cualquiera que sea el marco de referencia con el cual se trabajará? La innovación es la energía que impulsa a través de los cul de sac - los callejones sin salida - y lleva de nuevo al camino. 
ARTE \& DISEÑO, ISSN: 1692-8555, Vol. 10 Núm. 2, Julio - Diciembre de 2012 ODÍN ARREGOCÉS SERRANO

Una de las razones de la "búsqueda de creatividad" en la época presente es que las anomalías se están acumulando tan rápido en esta civilización tecnológica, velozmente creciente y cambiante, que es indispensable la innovación constante, tan solo para no perder el paso. Hoy ha surgido una variable nueva, que amenaza con volverse un nuevo ícono social: la velocidad de cambio, que incluye la asimilación del nuevo "paso" adquirido.

El consumo en una sociedad de desperdicio, por ejemplo, ha producido cantidades tan grande de basura, que es preciso empezar a ver el problema con nuevos ojos. Expertos de la Universidad sueca de Upsala, atribuyen hoy un kilo de basura diario por persona en este planeta globalizado, o sea unos 365 kilos al año por persona, Multiplíquese por siete mil millones y la cifra adquiere dimensiones aterradoras. De seguir así, a este mismo ritmo y sin una solución verdaderamente creativa a la vista, para el año 2050, sin duda, se habrá convertido este planeta en un gigantesco basurero.

De manera similar, las necesidades del mercado, junto con la reducción de la tierra cultivable según se la define tradicionalmente y la necesidad de alimentar más personas crean una huella ecológica notable lo que también ha conducido a idear nuevas formas de cultivar o incluso a sembrar en tierra rellena de sal, bajo la tierra o en el espacio exterior.

De seguir creciendo la población mundial - hoy estimada en siete mil millones de seres humanos - para el año 2050 habitarán el planeta doce mil millones de personas, una cifra totalmente alucinante. La población crece. El planeta no. Sigue siendo el mismo. Y eso no va a cambiar.

No obstante, las anomalías no explican la creatividad. Pueden ser una condición necesaria, pero no suficiente. La condición suficiente es la personalidad creativa, que interactúa con un ambiente que le transmite ciertas alternativas y posibilidades.

Una vida es una vida en particular. Es un hecho individual y único. No hay un ingrediente universal que haga creativa a una persona. Simplemente no existe. Puede haber tantos procesos creativos como personas creativas haya. De ahí que pueda decirse que "existe tanta felicidad en este mundo, como personas capaces de imaginarla"(García Márquez, 1978). Un cuadro completo de la creatividad requeriría de muchas imágenes. Sin embargo, como resultado de las entrevistas (Arregocés, 2003), con gente creativa se confirmaron varias características manifiestas respecto a la naturaleza del comportamiento creador: la gente creativa tolera la ambigüedad.

La gente creativa posee lo que el poeta norteamericano John Keats (2002) llamaba "capacidades negativas" o "la capacidad de sentirse a gusto en medio de misterios y dudas, de lo desconocido, sin ningún anhelo exasperado de hallar hechos o razones". Tienen el deseo incesante de crear un orden nuevo y satisfactorio a partir del caos, y el valor de persistir en el intento de crear dicho orden, bajo sus propias condiciones. Esto los torna con frecuencia pendencieros, algunas veces exasperantes, siempre únicos, siempre originales. Amantes perdidamente enamorados de "la primera vez" (siempre hay una primera vez). Lo que les interesa no es lo que los demás piensan de ellos, sino lo que ellos piensan de sí mismos. Están siempre dispuestos a dar "el paso más allá"; afrontar riesgos y emprender un nuevo rumbo. La gente creativa no teme EMPEZAR de nuevo.

\section{" La creatividad humana es un estado superior del alma y del conocimiento, es un nivel de conciencia perceptiva único, de seres únicos, que poseen una inteligencia y una vida igualmente únicas."}

La vida de perpetuo movimiento del director cinematográfico norteamericano John Huston (2002), nutrido por una curiosidad infatigable - "la curiosidad mató al gato" - se reflejan en su personalidad y su creatividad como director de cine.

Norman Lear (1984) rompió el molde de la típica comedia de TV y creó algo nuevo. Afrontó temas serios que volvió al revés - como una chaqueta de doble faz - hasta encontrar el humor que los reviste. Descubrió que hasta el tema más serio tiene lado ridículo y los mostró juntos, sin miedo, y fue un éxito. Fred Smith, heredero de una gran fortuna de El Paso, Texas, arriesgó su caudal y algo más, tuvo una gran fe en sí mismo para crear Fed-ex - Federal Express - y ponerlo al servicio de una economía electrónica, que se mueve a la velocidad de la luz. Una idea multimillonaria por la que obtuvo, por cierto, una baja calificación cuando la expuso en una monografía en sus estudios para la licenciatura en finanzas en la Universidad de Nueva York.

Claro que se trata de excepciones. De seres excepcionales. De alguna manera, lograron mantener vivo en ellos el "innerchild", el niño interior que todos los seres humanos llevan dentro, ese asombro infantil que permite "ver" con ojos nuevos. La capacidad de asombro disminuye en muchas personas cuando llegan a la edad adulta y les surge el miedo al ridículo. Incitar a los niños a pensar con originalidad es una forma de provocarlos a que se autoeduquen. La audaz falta de conformismo de los pequeños queda sofocada en la adolescencia a causa de los prejuicios de sus camaradas.

Resulta fácil comprender que la tarea no es tanto descubrir por qué hay gente creativa, sino averiguar por qué la mayoría nunca utiliza la creatividad. La gente creativa "se salta los límites", y es capaz de permanecer fuera del camino común, conforme avanza en edad, sin llegar a desorientarse. Detestan las palabras "pastor, masa, rebaño, borrego, uniforme, conductor". Freddie Mercury (1983), el desaparecido vocalista de la maravillosa banda británica de rock "Queen" - fallecido hace 20 años - escribía: "Para ser creativo, es necesario aprender a desconectar 
el juicio y conectar la imaginación. Si pudiéramos permitir que el niño que hay en nosotros siguiera correteando libremente".

Otro resultado de las entrevistas realizadas con arquitectos, artistas plásticos, diseñadores, hombres de letras, ciencias y líderes sociales de la más variada condición es que tienen egos poderosos y un fuerte sentido de identidad. Un elemento parece significativo en ella. (Samson Raphaelson, 1966) Alguien los tocó a edad temprana y los hizo conocer su valía al decirles: "Tú eres importante". Samsom Raphaelson recibió una carta estimulante de un editor a quien le había enviado sus primeros relatos y "me convertí en persona". Pablo Milanés cantaba en 1970 en la cafetería de la Universidad Central de la Habana - en sus tiempos libres - hasta que su casa se vio invadida de cartas y notas congratulatorias por la inmensa belleza de su arte: “Comprendí que mi música ya no me pertenecía. Me estaba convirtiendo en un instrumento de mí mismo, y así ha sido desde siempre. Hoy, mi público es lo más grande que ha podido sucederme", (P. Milanés, 1998) anota el músico popular cubano contemporáneo.

Para que florezca la vida interior, todos necesitan que alguien los toque. Sin embargo, esta fuerza del ego debe tener algo que ver con la necesidad de probar la propia valía por medio del ejercicio de la creatividad independiente. No es sorprendente que quien fue firmemente aprobado por una persona poderosa, quiera establecer más tarde una identidad independiente. De ahí el inmenso impulso de crear.

Impulso implica disciplina. La disciplina permite seguir las propias ideas a pesar del desaliento y el fracaso. Los inventores que buscan un mercado para nuevas ideas saben que, no importa cuán ingeniosas sean estas, nueve de cada diez ideas fracasan. Omara Portuondo, según sus propias palabras, lo tenía todo en su contra: negra, mujer, cubana, revolucionaria, pobre, tercermundista e hispanoparlante.

La perseverancia, la fortaleza para no rendirse, la fuerza para vencer al mundo en lugar de ser vencido por él: todo esto caracteriza a la persona creativa. También la capacidad para el trabajo arduo y constante, la fascinación por el "destello bisociativo" de Arthur Koestler (1998) - el momento del impacto intuitivo, el punto de "Eureka", "lo encontré" - hace olvidar los largos años de transpiración que condujeron a la inspiración. Los arquitectos, artistas, diseñadores, científicos, escritores e inventores manifiestamente creativos nunca parecen dejar de trabajar, ni aún en sus sueños.

Aún así, una cosa es describir a la persona creativa, y otra muy distinta describir el proceso creativo. Casi lo único en que concuerdan los expertos es en que la creatividad ocurre cuando dos ideas aparentemente inconexas se unen de tal manera que producen algo nuevo, un nuevo orden de cosas. El CIAM , la primera gran reunión de la Arquitectura Moderna donde se habló de creatividad como arma e instrumento de cambio concluye que "la esencia del significado de creatividad es la innovación, la capacidad de ir más allá de las pautas y normas conocidas".
No todo lo nuevo es creativo, por supuesto. Para que sea creativa, la novedad debe demostrarse a sí misma generando comprensión: debe ayudar a ver al mundo o a cada ser humano de un modo nuevo. Con la comprensión, se libera energía que transforma nuestra actitud y, en última instancia, nuestra conducta. Esta prueba de transcendencia redime a la creatividad al distinguirla de la novedad, dándole su valor verdadero: la novedad misma. ¿Cómo se alcanza ese estado de atención - alerta en la que nuestra percepción salta a nuevos terrenos? Sigue siendo un misterio, tanto para el erudito como para el investigador.

En la última década, se ha desatado una avalancha de investigaciones sobre el vínculo entre la creatividad y el proceso biológico que la acompaña, pero no se ha llegado a conclusión alguna.

El sicólogo Colin Martindale (1981), por ejemplo, ha observado diferentes formas de ondas cerebrales en estudiantes a quienes se incita originalmente a ser creativos. Ciertas personas, informa, producen más ondas alfa que otras cuando se les asigna una tarea creativa. "Se emocionan y participan - dice Martindale (1981) - en tanto que la gente menos creativa se torna suspicaz o incluso hostil", cuando se enfrenta a lo novedoso, ya sea en proyectos, música o ideas.

\section{CONCLUSIÓN: ¿SE HACE?... ¿SE ADQUIERE?}

La investigación prosigue muy de prisa y el profano forzosamente se queda atrás. La civilización cibernética actual se reconoce a sí misma como fundamentalmente creativa. Pero incluso los más escépticos que podrían argüir que creatividad es una palabra "altisonante y de sabor petulante" reconocen también que es ineludible. Algunos científicos concuerdan en que, la capacidad creativa -en cualquier forma que se la conciba, puede aprenderse. No es un hecho científicamente demostrable que cada niño que viene al mundo traiga un potencial creativo, es más bien, una declaración de fe.

Se puede imaginar una sociedad plenamente resuelta a lograr que toda la gente tenga la posibilidad de influir en la calidad de su vida cotidiana. Lograr eso es, según Henry David Thoreau (1968), "la más elevada de las artes". Así que creatividad es el nuevo horizonte. No existe ninguna otra alternativa, la vida misma es el mayor espectáculo permanente de creatividad. Nada en la vida está terminado. Todo, la propia vida es un eterno proceso permanente de metamorfosis. La vida es una transformación constante. Creatividad es la apoteósis del cambio coherente. Dante Alighieri escribió la "Divina Comedia" en siete días. Johann Wolfang Von Goethe(1999), escribió El Fausto en 25 años. Cuando se le increpó y se le dijo: ¿Maestro: cuándo va a terminar la obra? el genio respondió: "Acabaré cuando termine, cuando esté terminado. Antes no". Y así fue. No hay forma humana posible de impedir el ejercicio de la imaginación. Nada ni nadie pueden coartar el deseo irrefrenable de dar a luz lo "nuevo".

El mejor profesional de un arte o un oficio, empieza siendo
21 
siempre el mejor aficionado. La creatividad humana es un estado superior del alma y del conocimiento, es un nivel de conciencia perceptiva único, de seres únicos, que poseen una inteligencia y una vida igualmente únicas. El gran mensaje final, es claro y ennoblecedor: para todo aquel que haya dedicado lo mejor de sus vidas al ejercicio creativo, no existe éxtasis más poderoso, que el acto de crear algo nuevo, el ejercicio de la capacidad creativa. Tan grande es ese momento, tan poderoso es ese instante, que es el único verdadero tiempo en que los seres humanos pueden sentirse dioses, sentirse parecidos a Dios.

\section{REFERENCIAS BIBLIOGRÁFICAS}

Arregocés Serrano, Odín - “Entrevistas con personas con prestigio de ser creativas". Escritos libres. Primera edición. Barranquilla Colombia -2003.

Cesarani Obe, David - "Arthur Koestler: The Homeless mind." Primera edición Philadelphia - 1998.

Cuero Rengifo, Raúl - “Como ser creativo para triunfar”. Primera edición. Bogotá D.C. - Colombia - 2012.

Einstein Koch, Albert - "The Collected Papers of Albert Einstein. Vol.1. The early years, 1879 -1902". Segunda edición. NYC. 1982. García Marquez, Gabriel. “Cien años de soledad". Segunda edición. México D.F - 1978.

Huston Marcellus, John. “Las 500 mejores Peliculas de la Historia" . Primera edición - NYC - 2002.

Keats Jennings, John. "La caída de Hiperión (Un Sueño)"- Segunda edición - Madrid - España - 2002.

Kierkegaard, Aabye Sören - “Obras Completas - 1971" - Tercera edición - Frankfurt main - 2012.

Lear Milton, Norman - "Entrevista by aish staff". Primera edición - NYC - 2003.

Malamud Fidelman, Bernard - "Una nueva vida" - Segunda edición - Chicago - 1961.

Martindale Calgary, Colin R.- "Cognition and Consciousness" (The dorsey series in psychology) - Primera edición - Boston - 1881. Milanés Arias, Pablo - “Entrevista, Cubavisión”. Primera edición La Habana - Cuba - 1998.

Nietzsche, Fiedrich Wilhelm - "Obras completas, en prensa” (Volumen I: escritos de juventud). Quinta edición - Madrid - 2011. Oppenheimer Friedman, Robert Julius - "The open mind" - Primera edición - New York - 1955.

Prince, George M. - "La práctica de la creatividad” - Primera edición - New York 1970.

Rabil, Albert Jr. - "Humanism and pre-reformation theology". Volume 1,2,3. (Humanism and the disciplines). Primera edición Philadelphia - 1988 -Autor 1 .

D'amico, John F. I "Humanism and pre-reformation theology". Volume 1,2,3. (Humanism and the disciplines). Primera edición - Philadelphia - 1988 -Autor 2.

Raphaelson, Miles Samsom. “Entrevista a raíz de “Trouble in Paradise", el film - Nueve películas con Ernst Lubitsch" - New York - 1966.
Smith, Frederick Wallace. "Profile in Fortune Magazine's innovators hall of fame" - Primera edición - NYC -2001.

Theilard de Chardin, Pierre. "Obras completas". Tercera edición - Paris - 2011.

Thoreau Henry, David. “Paraiso (1843)". Quinta edición - New York - 1968.

Volpe Darling, Emilio - “El gesto del traspatio - poemas". Primera edición - Barranquilla - Colombia - 1999.

Von Goethe, Johann Wolfang. - "Las afinidades electivas" - Cuarta edición - Madrid - 1999. 